\title{
Water Supply Accessibility and Associated Factors Among Households of Jigjiga Town, Eastern Ethiopia
}

\author{
Email address: \\ derejeab7@gmail.com (D. A. Chekol) \\ ${ }^{*}$ Corresponding author
}

Dereje Abate Chekol", Tesfaye Gobena, Bezatu Mengiste

College of Health and Medical Sciences, Haramaya University, Harar, Ethiopia

\section{To cite this article:}

Dereje Abate Chekol, Tesfaye Gobena, Bezatu Mengiste. Water Supply Accessibility and Associated Factors Among Households of Jigjiga Town, Eastern Ethiopia. Landscape Architecture and Regional Planning. Vol. 5, No. 1, 2020, pp. 1-11. doi: 10.11648/j.larp.20200501.11

Received: October 8, 2019; Accepted: December 25, 2019; Published: February 11, 2020

\begin{abstract}
Access to improved water source for drinking and other domestic uses is a major developmental challenge in many developing countries like Ethiopia due to its different geological formations and climatic conditions water distribution is uneven spatial and temporal across Ethiopia country. Even though accessible water supply is a critical issue to ensure the quality of life there no study conduct on Water accessibility in Jigjiga town before, therefore this study was aimed to assess the accessibility of water supply and associated factors among residents of town on May 2016. Community based cross sectional study design was used and 408 households and 14 key informant was randomly and purposive selected for quantitative and qualitative approaches respectively. All independent variables with $\mathrm{p}$ - value of $<0.3$ at bivariate analysis were included in multivariate model to determine the predictors of the outcome variable, and to control the confounding factors. Overall $56.7 \%$ of households reported using an improved water source as the main source of drinking water supply within recommended distance and only $35.2 \%$ of households consume 20 liters per person per day and less than half households $(44.8 \%)$ affordable to water supply access (pay less than five percent of their income). Combining these three indicators results only a fifth of households (19\%) of households accessible to water supply that meet standard. Head of household with higher level of education [(AOR=4.2, 95\% CI $(1.0,18.06)]$ and those having private pipe water supply [( $\mathrm{AOR}=19.1,95 \% \mathrm{CI}:(5.1,71.39)]$ were identified as positively significant associated factors with water accessibility compared to those who cannot read and write and those that share water from neighbor pipe respectively. Access to water supply in the study area was very low. Therefore, those local authorities must pay special emphasis to improve accessibility and reliability of water supply and closely supervise and monitor private water vendors. Further in-depth studies should also be encouraged to look for improved interventions.
\end{abstract}

Keywords: Accessibility, Affordability, Household, Water Source

\section{Introduction}

Access to improved water for drinking and other domestic uses, such as bathing, cooking and washing of clothes, is a major developmental challenge in many developing countries. Almost 1.1 billion people worldwide do not have access to clean water and over twice this number, more than 2.5 billion, lack access to basic sanitation facilities. More than $80 \%$ of these 2.5 billion people are in Asia and Sub- Saharan Africa as documented by the World Health Organization (WHO) and the United Nations Children Fund (UNICEF) in 2009 [1]. In a WHO 2010 study, it was reported that only $35 \%$ of the urban population in Sub Saharan Africa have access to a piped water connection in their households [2].
The MDG drinking water target, to halve the proportion of the population without sustainable access to safe drinking water (an increase in coverage from $76 \%$ to $88 \%$ ) between 1990 and 2015, was met in

2010. Between 1990 and 2012, 2.3 billion people gained access to an improved drinking water source; raising global coverage to $89 \%$ in 2012 . There has been an impressive growth in the use of piped connections to a dwelling, plot or yard. Approximately $70 \%$ of the 2.3 billion people who gained access to an improved drinking water source between 1990 and 2012 gained access to piped water on the premises. Seventh percent of the 1.6 billion people who gained access to piped water on premises live in urban areas [3].

Africa has the lowest water supply and sanitation coverage 
of any region in the world. More than $30 \%$ of Africans residing in urban areas currently lack access to adequate water services and facilities. In the year 2000, WHO estimated that Africa contains $28 \%$ of the world's population without water access to improved water supplies, and $13 \%$ of the world's population, are without access to improved sanitation. Only $62 \%$ of the people in African countries have access to improved water supplies, and only $60 \%$ have access to improved sanitation [4].

Access rate to improved water supply sources hardly increased in urban Sub-Saharan Africa since the late 90's. The percent of the urban population that had access to improved water supply only increased from 67 in the late 90 's to 69 percent in the late 2000's. This represented an increase of 63 million urban dwellers gaining access to improved water supply from 135 to about 199 million since late 90's.

According to EDHS (2011) report, more than half of the households in Ethiopia (54 percent) have access to an improved source of drinking water, with a much higher proportion among urban households (95\%) than among rural households $(42 \%)$. The most common source of improved drinking water in urban households is piped water, used by 87 percent of urban households. In contrast, only 19 percent of rural households have access to piped water. Eleven percent of rural households have access to drinking water from a protected spring, and 8 percent have access to drinking water from a protected well. Nationally, the proportion of Ethiopian households with access to piped water has increased from 18 percent in 2000 to 24 percent in 2005 and 34 percent in 2011. In the last six years there has been a rapid increase in the percentage of households in Ethiopia that use some type of improved source of drinking water, from 35 percent in the 2005 EDHS to 54 percent in the 2011 EDHS [5].

The U. N. Committee on Economic, Social, and Cultural Rights defines the water in the following way: "The human right to water entitles everyone to sufficient, safe, acceptable, physically accessible and affordable water for personal and domestic uses." The Committee has identified five-core components quality, accessibility, acceptability, affordability and availability as comprising the human right to water, which together are "indispensable for leading a life in human dignity." Quality and affordability, the aspects of the right of primary importance to the communities described in this hearing request, have been defined and provide important standards for affected communities and governments alike. Quality is defined as water that is safe and does not pose a threat to human health. Affordability refers to economic accessibility, includes all direct and indirect costs for securing water for domestic use, and should not compromise the realization of other human rights. In 2010, the General Assembly adopted a resolution recognizing the right to water and sanitation, and acknowledged the "importance of equitable access to safe and clean drinking water and sanitation as an integral component of the realization of all human rights" [6].

Water is the core constituent of the human body and most of the living species in this planet. A minimum quantity of water must be available for individuals not only for their survival but also for their various domestic needs to sustain good health. Domestic water supplies are one of the fundamental requirements for human life. Without water, life cannot be sustained beyond a few days and the lack of access to adequate water supplies leads to the spread of disease. Countries with different stages of development tend to have different water supply and demand status. The lack of safe drinking water, particularly in developing countries, is becoming an increasingly serious global topic. Developed countries are more likely access to water than developing countries. For instance in sub-Saharan Africa only $60 \%$ of the total population in the sub-continent is using improved sources of drinking water [7].

Pertinent information on household's water accessibility is necessary to properly assess the factors that affect water accessibility. Several factors affect water accessibility of the households. According to the studies that have been conducted in different areas including in Ethiopia, water accessibility could be affected by different factors. Some of these factors are socio-demographic factors as gender, age, education, income, household size, housing condition; nature of employment and topographical variation; water source and its type [8].

Provision of physically accessible and affordable water for personal and domestic uses is not only a socioeconomic and developmental issue, but also an issue of self-respect, human dignity and public health [6]. Therefore, this study was designed to assess accessibility of water supply in Jigjiga town to give insight about magnitude of the problem.

\section{Methods and Materials}

\subsection{Study Area and Study Period}

The study was conducted in Jigjiga city administration from May 15- 30, 2016. This is located in the Faffan zone of, Somali region that is $631 \mathrm{~km}$ from Addis Ababa. Jigjiga city administration has an estimated total population of 159,300 of whom 81,789 are men and 77,511 are women Based on the Central Statistical Agency Ethiopian city and towns population estimation projection of 2015. The four largest ethnic groups reported in this town were the Somali $(61.58 \%)$, the Amara (23.25\%), the Oromo (7.32\%), and the Gurage (4.37\%); all other ethnic groups made up $3.48 \%$ of the population. This city is added some rural settlement from Jigjiga woreda.

As Jigjiga town water supply project data shows the only promising, water resource for Jigjiga town water supply project is ground water. In the existing system there are more than 21 boreholes drilled to serve the town.

\subsection{Study Design}

A community based cross sectional study using quantitative techniques and complemented by qualitative methods was used.

\subsection{Population}

\subsubsection{Source Population}

All households in Jigjiga town

\subsubsection{Study Population}


All households in the four randomly selected Kebeles (kebele 05, 08, 12 and 15)

\subsubsection{Study Units}

Selected households from Study population

\subsection{Inclusion Exclusion Criteria}

\subsubsection{Inclusion Criteria}

a) A household (home) which is normally used only for residence and respondent should be resident in the household for more than six months and illegible respondent above 18 year

b) For Key informants interview (KII) the respondent should have stayed more than three month in the office

\subsubsection{Exclusion Criteria}

Household if illegible respondent is absent (due to illness or age).

\subsection{Sample Size Calculation}

For the specific objective one

To determine the required data, representative sample size will be determined using formula for a single population proportion based on the following assumptions, Margin of error 5\%, Confidence level 95\%, Contingency for non-response rate $10 \%$. Water supply accessibility of Awaday town is $39 \%$ in 2012 [9]. Let as Jigjiga town accessibility is the same. $\mathrm{P}=39 \%$

$$
n=\frac{(Z \alpha / 2)^{2} p(1-p)}{d^{2}}
$$

Where, $\mathrm{n}=$ the total sample size required $\mathrm{d}=$ marginal error

$\mathrm{Z} \alpha / 2=$ critical value $=1.96$

$\mathrm{P}=$ urban water supply accessibility of the region. $=39 \%$

Thus, the sample size will be as follows.

$$
\mathrm{n}=\frac{(1.96)^{2} 0.39(1-0.39)}{(0.05) 2}=366
$$

1. Total number of sample size required for the study $=366$

2. Non-response rate of $10 \%(366)=37$.

3 . Total sample size required for the study is $37+366=403$. For the specific objective two

Epi- info version 7.1.4 is used to calculate the sample size for the second specific objective: using double population proportion formula with the following assumption: power of the study to be $80 \%, 95 \%$ confidence level to be 1.96 , and the ratio of unexposed: exposed is almost equivalent to 1 . A study done in 16 town of Ethiopia shows that sex differential of household head were statistically significant on using improved drinking water source, i.e. female-headed households depend on unimproved water sources $(23 \%)$ than male-headed households (12\%) (P-value $<0.001)$ ([10])

The required sample size is calculated using an equation:

$$
n_{1}=\frac{\left[Z_{\alpha} \sqrt{\left(1+\frac{1}{r}\right) P(1-P)}+Z_{\beta} \sqrt{P_{1}\left(1-P_{1}\right)+\frac{P_{2}\left(1-P_{2}\right)}{r}}\right]^{2}}{\left(P_{1}-P_{2}\right)^{2}}
$$

$\mathrm{n} 1=$ sample size of households that used improved drinking water sources were headed by females

$\mathrm{n} 2=$ sample size of households that used improved drinking water sources were headed by males

$\mathrm{r}=\mathrm{n} 1 / \mathrm{n} 2=2$ that is taking one to 2 ratio.

$Z \alpha / 2=1.96$ for the standard scale of $95 \%$ level of confidence, $Z \beta=0.84$ considering $80 \%$ of power to detect a difference of (P1-P2) 8\%

p1 = proportion of households headed by females, $23 \%$

p 2 = proportion of households headed by males, $12 \%$

Let $\mathrm{P}($ pooled population proportion $)=\frac{p 1+r p 2}{1+r}$

\begin{tabular}{|c|c|c|c|c|c|}
\hline Specific objective & Proportion/Factor (p) & & $\begin{array}{l}\text { Calculated } \\
\text { sample size }\end{array}$ & $\begin{array}{l}\text { Non-response } \\
\text { rate }(10 \%)\end{array}$ & $\begin{array}{l}\text { Total sample } \\
\text { size }\end{array}$ \\
\hline 1 & \multicolumn{2}{|c|}{$39 \%$ Proportion of water supply accessibility. } & 366 & 37 & 403 \\
\hline 2 & Head of Household respondent & $\begin{array}{l}\text { Male (12) } \\
\text { Female (23) }\end{array}$ & & & 408 \\
\hline
\end{tabular}

$$
\mathrm{P}=(\mathrm{p} 1+\mathrm{rp} 2) / 1+\mathrm{r}=23+2 * 12 / 1+2=16
$$

Table 1. Sample size calculation for single population proportion.

Therefore, the maximum sample size 408 will be taken as a study participant.

\subsection{Sampling Procedures}

\subsubsection{Sampling Procedures for Quantitative Method}

Stratified sampling technique was used to select the study population. First, 18 kebeles will be identified and further stratified in to two strata based on the previous administration 10 kebeles (01-10) and the new settlement 8 kebeles (11-18) added from Jigjiga woreda, then from each stratum, two kebeles will be randomly selected for the study. Secondly 403 households will be randomly selected from the study kebele based on population proportion of kebele, thirdly study unit was randomly selected from households list of each kebeles administration office then the first study unit was selected randomly from the first 19 listed households then systematic sampling method was followed for the next continuing study unit using kebeles population proportion for assigned sample size $=\mathrm{Kth}=\mathrm{n} / \mathrm{N} \quad(7771 / 403=19)$, which mean every the 19th household was selected.

\subsubsection{Sampling Procedures for Qualitative Method}

In order to complement the data obtained by the use of structured questionnaires a total of 14 KII participants were selected from Water Supply office, Health office, Municipality office who is professional related and have experience in water supply and sanitation field of study and also kebele 
administrative members who working with water and sanitation committee. Three (2) KII participants were selected from each office and kebeles. Principal investigator (PI) selected a participant for KII. Semi-structured questionnaires, which are open ended, was used to guide the interview.

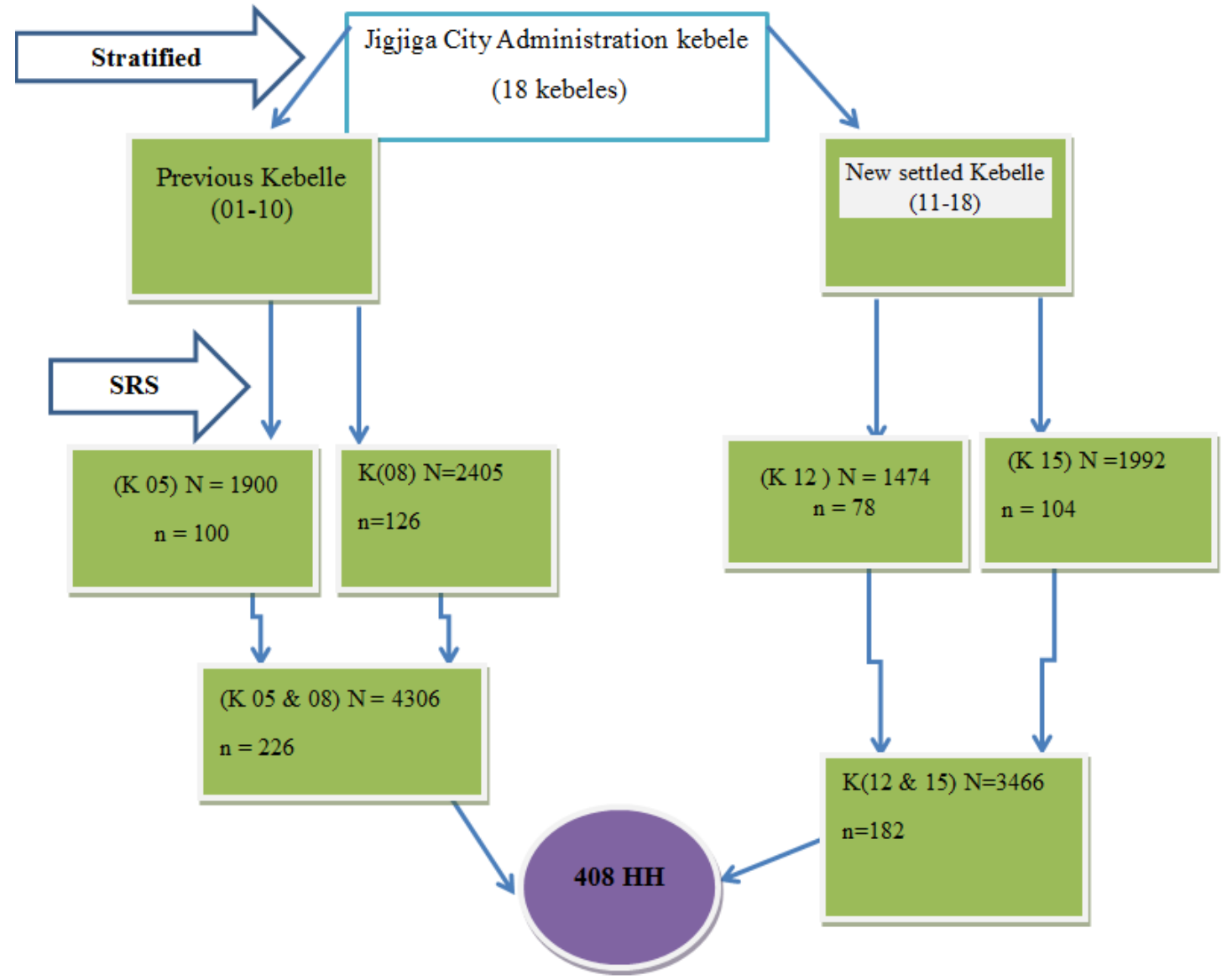

Figure 1. Schematic presentation of quantitative sampling technique for assessment of Water supply accessibility \& associated factors in Jigjiga town, Ethiopia 2016 .

\subsection{Method of Data Collection}

\subsubsection{Quantitative Method}

The data will be collected using structured questionnaires, personal observation and checklist specially developed for this purpose by interviewing the respondents.

The questionnaires will be initially prepared in English and then translate into Amharic and Somali language. The Amharic and Somali version will again be translated back into English to check for any inconsistencies or distortion in the meaning of words and concepts.

Ten Health Extension Workers who can speak the local language will be recruited as data collectors and the data will be collected through house to house survey from illegible respondent of household member who resident in the household for more than six months. Two supervisors will be selected from Jigjiga city health and education office that have B. Sc. /BA holders. The responsibilities of the supervisors will be checking whether the questionnaires are correctly completed or not. The enumerators and supervisors will be given training for three days on procedures, techniques and ways of collecting the data. The questionnaires will be pretested in the kebele 09 that is similar to the study population before beginning the actual data collection process and the necessary modification will be made.

\subsubsection{Qualitative Methods}

The principal investigator (PI) moderated KII with the assistance of trained note taker and tape recorder. Semi-structured questionnaires, which are open ended, was used to guide the interviews.

\subsection{Operational Definitions}

Accessible water supply: the availability of water at least 20 Littre per capital per day from improved source within 200 meter of the user's dwelling or no more than 30 minutes one way to collect water and queuing time should be less than 15 minutes and it should not take more than 3 minutes to fill a 20 Littre container [11] and water is deemed economic accessible (affordable) if a family's or household's monthly income spent on it does not exceed 5\% [12].

Household: in Ethiopian context, a person or group of persons, whether or not they are related, who normally live together in the same housing unit or group of housing units and who have common cooking arrangements. 


\subsection{Study Variables}

Dependent Variable:

Access to water supply

Independent Variables:

Socio-demographic factor

Sex of heads of households, marital status, Household size, Income, Education and Tenancy

Water related factor

Type of source, Distance from source, Amount \&Water Price

Institutional factor

Maintenance service

Technical factor

Functionality

\subsection{Data management and Dissemination}

\subsubsection{Data Quality Assurance}

The questionnaire was translated into the local languages i.e. Somali and Amharic for data collection and then retranslated back into English. Two days training was provided to the data collectors and supervisors on the data collection tool and the data collection procedure. Then the questionnaire was pretested on $5 \%$ of the sample size out of the study area to ensure its validity. The supervisors and the principal investigator supervised data collectors closely. The principal investigator and the supervisors on daily basis checked completeness of each questionnaire. Two data clerks entered data and consistency was crosschecked by comparing the two separately entered data on EpiData. Finally, multivariate analysis was run in the binary logistic regression model to control the confounding factors.

\subsubsection{Data Processing and Analysis}

The data were first coded, entered and cleaned using EpiData version 3.1 and exported to SPSS statistical software version 16.0 for analysis. Descriptive statistical analysis such as simple frequencies, measures of central tendency and measures of variability were used to describe socio demographic characteristics of participants such as sex of household head, ethnicity, religion, educational level, marital status, occupation, tenancy and income. Then the information was presented using frequencies, summary measures, tables and figures.

Water accessibility was analyzed by computing WHO and Water Aid criteria, WHO Component score was computed based on source, distance, time and quantity (consumption rate) and finally Water Aid criteria cost affordability was computed to analysis overall water accessibility and associated factors among households.

On bivariate analysis, crude odds ratio with $95 \%$ CI was used to see the association between each independent variable and the outcome variable by using binary logistic regression.
Independent variables with p-value of $<0.3$ were included in multi-variable analysis to control the confounding factors. Then outliers and influential cases were checked by standardized residuals and cook's distance respectively. Cases with standardized residuals out of the interval $(-3,3)$ and cook's distance above one were excluded from the multivariable analysis. Odds ratios with 95\% CI were estimated to identify the factors associated with water accessibilities using multivariable logistic regression analysis. Level of statistical significance was declared at p-value < 0.05 .

\subsubsection{Ethical Considerations}

Ethical clearance was secured from Haramaya University, College of Health and Medical Science, Institutional Health Research Ethics Review Committee (IHRERC). Support letter was also written from Somali regional health bureau to Jigjiga Town water supply and sewerage authority. Informed written consent was obtained from each participant after explaining the purpose and benefits of the study. Confidentiality of the study participants' information was also ensured.

\subsubsection{Information Dissemination}

The report of the study will first be submitted and presented to Haramaya University, and then the copies of the report will be submitted to Somali regional health bureau, Jigjiga Town water supply and sewerage authority, Town Municipality, and Health Offices. Attempt will be made to present on national and international conferences and workshops. Besides, publication on peer-reviewed journal will be considered.

\section{Result}

\subsection{Socio-economic and Demographic Characteristics}

A total of 386 households were included in the study with a response rate of $96 \%$. Majority of household head 283 $(73.3 \%)$ were male. The average age of the respondent was $37(+11.29)$ years. The average family size of the respondents was found to be $6.4(+2.64 \mathrm{SD})$. The education level of the respondents ranges from minimum of not able to read and write to the maximum of college graduate. From the total respondents 54 (14\%) can neither read nor write, $53(13.7 \%)$ able to read and write, $74(19.2 \%)$ have completed primary education, $125(32.4 \%)$ have completed secondary school and the remaining $80(20.7 \%)$ have joined higher education. The data about the occupation of the respondent shows that 137 (35.5\%) was merchant, 119 (30.8\%) government employee, $56 \quad(14.5 \%)$ daily laborer, $68 \quad(17.6 \%)$ unemployed/pensioned and the rest $6(1.6 \%)$ was other (Table 2).

Table 2. Socio-demographic characteristics of respondent at Jigjiga Town Somali Regional State, of Eastern Ethiopia, May 2016.

\begin{tabular}{llll}
\hline s/no & Variables & & Frequency (\%) \\
\hline 1 & Sex of HHH $(\mathrm{n}=386)$ & Male & $283(73.3)$ \\
& & Female & $103(26.7)$ \\
\hline
\end{tabular}




\begin{tabular}{|c|c|c|c|}
\hline s/no & Variables & & Frequency (\%) \\
\hline \multirow{5}{*}{2} & \multirow{5}{*}{ Ethnic group of $\mathrm{HHH}(\mathrm{n}=386)$} & Somali & $240(62.2)$ \\
\hline & & Amhara & $77(19.9)$ \\
\hline & & Oromo & $32(8.3)$ \\
\hline & & Gurage & $22(5.7)$ \\
\hline & & Other & $15(3.9)$ \\
\hline \multirow{3}{*}{3} & \multirow{3}{*}{ HHH religion $(\mathrm{n}=386)$} & Muslim & $271(70.2)$ \\
\hline & & Orthodox & $102(26.4)$ \\
\hline & & Protestant & $13(3.4)$ \\
\hline \multirow{5}{*}{4} & \multirow{5}{*}{ Educational level of $\mathrm{HHH}(\mathrm{n}=386)$} & unable to read and write & $54(14)$ \\
\hline & & read and write & $53(13.7)$ \\
\hline & & Primary complete (6-8) & $74(19.2)$ \\
\hline & & junior complete (9-12) & $80(20.7)$ \\
\hline & & college and above & $125(32.4)$ \\
\hline \multirow{4}{*}{5} & \multirow{4}{*}{ Respondent marital status $(\mathrm{n}=386)$} & Single & $9(2.3)$ \\
\hline & & Married/partner & $343(88.9)$ \\
\hline & & Divorced/separated & $28(7.3)$ \\
\hline & & Widowed & $6(1.6)$ \\
\hline \multirow{5}{*}{6} & \multirow{5}{*}{ Occupation of HHH ( $\mathrm{n}=386)$} & Merchant & $122(31.6)$ \\
\hline & & government employee & $13(34.7)$ \\
\hline & & Daily labourer & $52(13.5)$ \\
\hline & & unemployed/pensioned & $73(18.9)$ \\
\hline & & Other & $5(1.3)$ \\
\hline \multirow{3}{*}{7} & & Private & $293(75.9)$ \\
\hline & Tenancy situation of respondent $(\mathrm{n}=386)$ & Kebele & $24(6.2)$ \\
\hline & & Rent from private & $69(17.9)$ \\
\hline
\end{tabular}

As results in table 2 indicate, majority 240 (62.2\%) of respondent were Somali and $271(70.2 \%)$ were Muslim in religion. Concerning house related situation majority 343 (88.9\%) and 293 (75.9\%) of the respondent were married and live in Private house respectively. The average monthly income of the household is Birr 2610.52 ranging from the maximum of Birr 8600 to the minimum of Birr 500 per month.

\subsection{Accessibility of Water Supply}

Of the total 386 households, $219(56.7 \%)$ of them use pipeline water supply that mean 138 (35.8\%), 33 (8.5\%) and $48(12.4 \%)$ use private pipe, standpipe and pipe water from neighborhood, respectively, and the remaining 167 (43.3\%) households got water from vendors which was not improved source (Table 3 ).

Table 3. Source of water supply for study participants, Jigjiga, eastern Ethiopia, 2016.

\begin{tabular}{llll}
\hline No & Water supply service status & Frequency & Percentage \\
\hline 1 & private pipe & 138 & 35.8 \\
2 & stand pipe & 33 & 8.5 \\
3 & Vendor & 167 & 43.3 \\
4 & Neighbour & 48 & 12.4 \\
& Total & 386 & 100 \\
\hline
\end{tabular}

Concerning water accessibility in terms of time and distance, out of 386 households the majority 305 (79.1\%) of them use on site or delivered to home and the remaining 81 $(20.9 \%)$ of them use offsite water supply. From those off site water supply users $46(56.7 \%)$ and $51(63 \%)$ of them get water less than 30 minutes of one way go and within 200 meters respectively as WHO 2003 guideline. Overall out of 386 households about $351(90.9 \%)$ and $356(92.2 \%)$ of them access to water supply in terms of time and distance respectively.

Besides, additional information was collected from respondents who had not pipeline connection. According to the information from 248 (59.6\%) households who are using water from public tap and vender or private seller, why they do not have private pipe water supply, about 91 (36.7\%), 58 (23.4\%), $52(21 \%), 43(17.3 \%)$ and $4(1.6 \%)$ of them were due to service unavailability (complicated procedures set by concerning body to get private connection), cost unaffordability, distance from main line, legality issue related with house and due to lack of space respectively

Table 4. Average water consumption levels of study participants, Jigjiga, 2016.

\begin{tabular}{llll}
\hline No & Average consumption l/p/d & Frequency & percentage \\
\hline 1 & $5-9$ & 4 & 1.0 \\
2 & $10-14$ & 114 & 29.5 \\
3 & $15-19$ & 132 & 34.2 \\
4 & $20-24$ & 114 & 29.5 \\
5 & $>25$ & 22 & 5.7 \\
\hline
\end{tabular}

Out of 386 households about 219 (56.7\%), 351 (90.9\%), $356(92.2 \%)$ and $136(35.2 \%)$ of them had access to water supply in terms of source, time, distance and quantity respectively. However only 85 (22\%) of them had access to water supply as WHO 2003 guide lines.

In addition to source, distance, time and adequacy, the affordability of water has a significant influence on the use of water and selection of water sources. Households with the lowest levels of access to safe water supply frequently pay more for their water than households connected to a piped water system. The high cost of water may force households to use small quantities of water and alternative sources of poor quality that represent a greater risk too (Public Health Protection, 2000). The study found that, only $170(44.8 \%)$ of households were access to water supply 
economically i.e. pay less than 5\% of their monthly in come as water aid 2011 criteria.

Table 5. The effects of water point on it accessibility, jigjiga, 2016.

\begin{tabular}{|c|c|c|c|c|c|c|c|c|c|c|c|c|}
\hline \multirow{2}{*}{\multicolumn{2}{|c|}{$\begin{array}{l}\text { Water accessibility criteria Verse } \\
\text { type of water source }\end{array}$}} & & \multicolumn{2}{|c|}{ private pipe } & \multicolumn{2}{|c|}{ stand pipe } & \multicolumn{2}{|c|}{ vendor } & \multicolumn{2}{|c|}{ neighbor } & \multicolumn{2}{|c|}{ Total accessibility } \\
\hline & & & No & $\%$ & No & $\%$ & No & $\%$ & No & $\%$ & No & $\%$ \\
\hline \multirow{2}{*}{1} & \multirow{2}{*}{ cost water accessibility } & access & 133 & $96 \%$ & 11 & $33 \%$ & 7 & $4 \%$ & 18 & $38 \%$ & 169 & $44 \%$ \\
\hline & & in access & 5 & $4 \%$ & 22 & $67 \%$ & 160 & $96 \%$ & 30 & $63 \%$ & 217 & $56 \%$ \\
\hline \multirow{2}{*}{2} & \multirow{2}{*}{ quantity water accessibility } & access & 72 & $52 \%$ & 11 & $33 \%$ & 44 & $26 \%$ & 9 & $19 \%$ & 136 & $35 \%$ \\
\hline & & in access & 66 & $48 \%$ & 22 & $67 \%$ & 123 & $74 \%$ & 39 & $81 \%$ & 250 & $65 \%$ \\
\hline \multirow{2}{*}{3} & \multirow{2}{*}{ source water accessibility } & access & 138 & $100 \%$ & 33 & $100 \%$ & 0 & 0 & 48 & $100 \%$ & 219 & $57 \%$ \\
\hline & & in access & 0 & & 0 & 0 & 167 & $100 \%$ & 0 & $\mathrm{~V}$ & 167 & $43 \%$ \\
\hline \multirow{2}{*}{4} & \multirow{2}{*}{ time water accessibility } & access & 138 & $100 \%$ & 18 & $55 \%$ & 166 & $99 \%$ & 29 & $60 \%$ & 351 & $91 \%$ \\
\hline & & in access & 0 & 0 & 15 & $45 \%$ & 1 & $1 \%$ & 19 & $40 \%$ & 35 & $9 \%$ \\
\hline \multirow{3}{*}{5} & \multirow{2}{*}{ distance accessibility } & access & 138 & $100 \%$ & 21 & $64 \%$ & 165 & $99 \%$ & 30 & $63 \%$ & 354 & $92 \%$ \\
\hline & & in access & 0 & & 12 & $36 \%$ & 2 & $1 \%$ & 18 & $38 \%$ & 32 & $8 \%$ \\
\hline & \multicolumn{2}{|c|}{ Average accessibility of Water point } & 89.6 & & $57 \%$ & & $46 \%$ & & $56 \%$ & & & \\
\hline
\end{tabular}

In table 5 the average accessibility of water supply was high affected by it source, i.e. accessibility of water supply was high for private pipe user and low for those buy from vendor.

Bar Chart

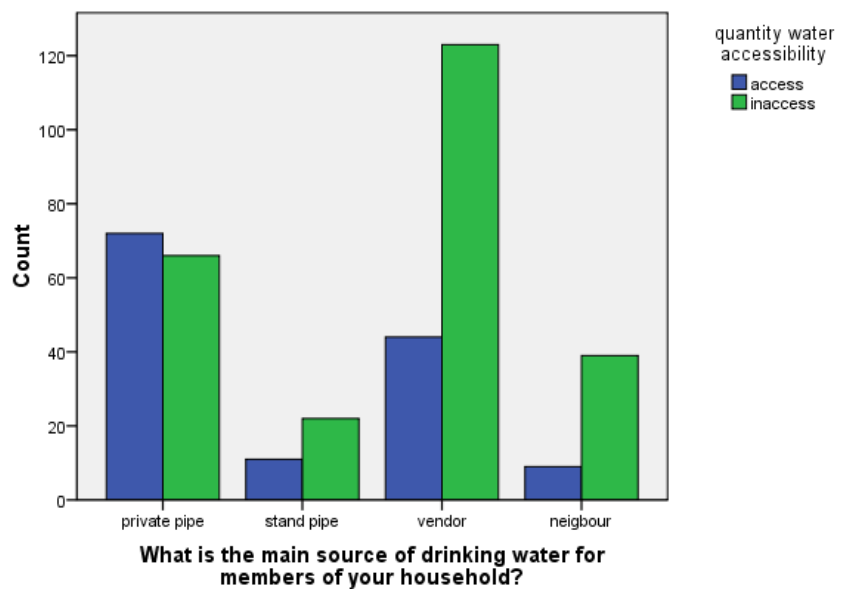

Figure 2. Type of water source and its accessibility in terms of quantity.

Cost accessibility of water supply was high for private pipe and very low for vendor (Figure 3).

\section{Bar Chart}

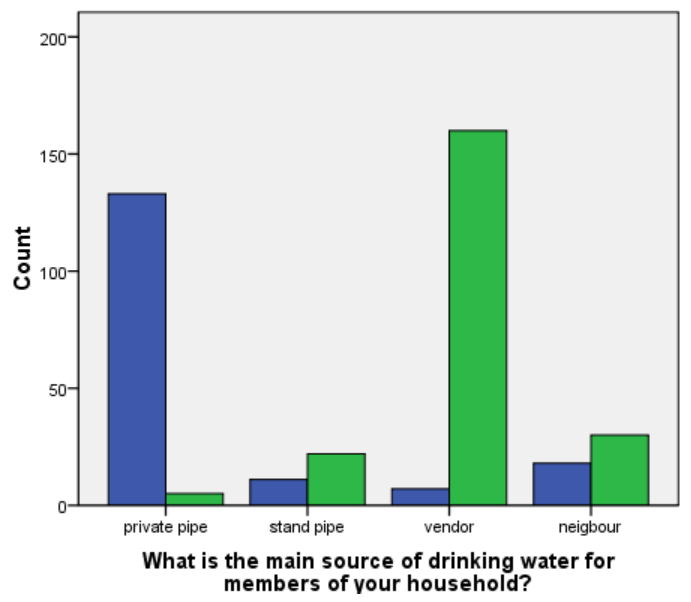

Figure 3. Type of water source and its accessibility in terms of cost.

\subsection{Water Supply Reliability}

According to field observation result, inefficient distribution of the provision of water supply service makes a systems or conditions more complicated in the town. The problem of line expansion was further exacerbated by steady and rapid spatial expansion of the town crossing the existing municipal boundary and influenced the pipeline extension which in turn influenced pipeline connection. As far as faces that were encountered by the community due to complete lack of water supply around this new expand, part of the town and peripheral area was high burden of people per public water points. This involving that many people were queuing at water points for long time that eventually result in tiredness for water collectors and time, energy and rarely disturbance occurred among people when wait in line disordered.

Besides to water reliability, out of 180 households only 17 $(9 \%)$ of the respondents have daily taped water access for their domestic consumption, from those 17 households only $2(12 \%)$ get daily 24 hours the left $15(88 \%)$ get daily at certain hour. Regarding how often they get taped water within a week, 42 $(26 \%)$ of the respondents have accessed to tape water less than once in a week, 39 (24\%) of the respondents have accessed taped water 1-2 days in a week, $80(50 \%)$ of the respondents have accessed taped water for their need 3-4 days in a week.

Concerning water interruption about 162 (92\%) of them were experience with water interruption. Regarding how the water interruption problem was difficult, the respondents 73 (45\%) mentioned that water interruption lasted for 2 to 3 days, $49(30 \%)$ said that the water interruption lasted for 4 to 5 days, $11(7 \%)$ stated that the interruption of water lasted for 6 to 7 days and $30(18 \%)$ claimed that the interruption of water lasted more than a week. Therefore, the majority of the respondents' water interruption lasted 2 to 3 days, 4 to 5 days, greater than week and 6 to 7 days, respectively. Regarding cause of water interruption, 83 (53\%) of the respondents stated that they didn't know the cause of water interruption, 37 (23\%) stated that water interruption occurred due to source/production problem, $38(24 \%)$ claimed that water interruption occurred as a result of technical problem.

Head of Jigjiga town water supply said that due to lack of alternative water source, water scarcity was main problem we couldn't met the recommended demand and supply because 
Jigjiga is one of the areas in the country with acute water shortage for animal watering. In the dry seasons, Pastorals from the surrounding $30 \mathrm{~km}$ radius are using water for their Animal Watering from the town's water supply system and there is no data regarding the number of animals served by the town's water supply system.

Regarding to service reliability Jigjiga town water supply technical person said that due to water scarcity we could not fit regular water supply (flow) in addition to this water interruption was another problem, which is occurred due to sedimentation of salt because of water hardness that lead clogging \& bursting of pipe.

Regarding respondent satisfaction about 344 (89\%) of the respondents were not happy at current water supply of the town, about 167 (49\%), 29 (9\%) 60 (18\%) 76 (22\%) and nine $(3 \%)$ constraints due to its scarcity, quality, interruption, cost and other reason respectively. Therefore, this result revealed that how much current provision of water services was full of constraints. As a result, dwellers had not get water continuously, this situation leads dwellers unsatisfied on current provision of water supply in the study area. Among this constraint with its scarcity, cost, interruption, and quality were the main problem, because of this about 131 (34\%) household rise complaint to concerned body out of them about $85(65 \%)$ said that there was no action for their complaint the left $19(15 \%) \& 27(21 \%)$ said that prompt and delay action taken for their complaint respectively.

A Chairman of three study kebeles said that, the scheme capacity was very low and unevenly distributed and also there was no person assigned for public stand pipe service, i.e. the key was on the hand of irresponsible person who was voluntary care taker due to nearest to stand pipe and no payment for her service so that she open (gave services) only when the time is comfortable for her, sometime the stand pipe opened during morning time which didn't stay more than an hour.

Besides, willing to pay for water service improvement information was collected as the result shows, about 304 (79\%) households were willing to pay for service improvement, out of them $94(31 \%), 146(47 \%) \& 69(22 \%)$ were willing to pay for house connected, yard and stand pipe service improvement respectively.

\subsection{Factors Associated with Water Accessibility}

On bi-variable logistic regression analysis household with monthly income above 4500 birr were [ $(\mathrm{COR}=5.82,95 \% \mathrm{CI}$ : $(1.86,18.22)]$ more likely had access to water supply compare to those their monthly income range between 500-1499 birr. Household those had private pipe were more likely $[(\mathrm{COR}=15.44,95 \% \mathrm{CI}:(4.58,52.06)]$ and those buy water from water vendor were less likely $[(\mathrm{COR}=0.09,95 \% \mathrm{CI}$ : $(0.01,0.89)]$ accessible to water supply compare to those use from neighbor private pipe.

Regarding educational status head of household those attend high school $[(\mathrm{COR}=3.1,95 \% \mathrm{CI}:(1.13,8.47)]$ and above college [(COR $=3.27,95 \% \mathrm{CI}:(1.14,9.34)]$ were more likely access to water supply compare to those unable to read and write.

Household those had private pipe were more likely $[(\mathrm{COR}=15.44,95 \% \mathrm{CI}:(4.58,52.06)]$ and those buy water from water vendor were less likely $[(\mathrm{COR}=0.09,95 \% \mathrm{CI}$ : $(0.01,0.89)]$ accessible to water supply compare to those use from neighbor private pipe.

Besides, to tenancy those live in their own house more likely $[(\mathrm{COR}=2.43,95 \% \mathrm{CI}:(1.06,5.56)]$ accessible to water supply compare to those rent from private.

In multivariable logistic regression analysis, household those college $\&$ above educational status $[(\mathrm{AOR}=4.2,95 \% \mathrm{CI}$ $(1.0,18.06)]$ were more likely accessible water supply compare to those cannot read \& write.

Besides, to water source those use private pipe water were [(AOR=19.1, 95\% CI: $(5.1,71.39)]$ more likely accessible to water supply compare to those use from neighbor pipe.

Table 6. Factors associated with water accessibility among households in Jigjiga Town of Eastern Ethiopia, May 2016.

\begin{tabular}{|c|c|c|c|c|c|}
\hline \multirow{2}{*}{ Independent variables } & \multirow{2}{*}{ Frequency } & \multicolumn{2}{|c|}{ Access to Water Supply } & \multirow{2}{*}{$\operatorname{COR}(95 \% \mathrm{CI})$} & \multirow{2}{*}{ AOR (95\% CI) } \\
\hline & & Yes $(\%)$ & No $(\%)$ & & \\
\hline \multicolumn{6}{|l|}{ Education level of $\mathrm{HHH}$} \\
\hline read and write & $53(14 \%)$ & $10(19 \%)$ & $43(81 \%)$ & $2.28(0.72,7.19)$ & $1.2(0.3,4.82)$ \\
\hline Primary complete (6-8) & $74(19 \%)$ & $10(14 \%$ & $64(86 \%)$ & $1.53(0.49,4.77)$ & $0.7(0.2,2.91)$ \\
\hline junior complete $(9-12)$ & $125(32 \%)$ & $30(24 \%)$ & $95(76 \%)$ & $3.10(1.13,8.48) *$ & $2.2(0.6,7.99)$ \\
\hline $\begin{array}{l}\text { college and above } \\
\text { income }\end{array}$ & $80(21 \%)$ & $20(25 \%)$ & $60(75 \%)$ & $3.27(1.14,9.34) *$ & $4.2(1.0,18.06) *$ \\
\hline $500-1499$ & $60(16 \%)$ & $7(12 \%)$ & $53(88 \%)$ & 1 & 1 \\
\hline $1500-2499$ & $120(31 \%)$ & $20(17 \%)$ & $100(83 \%)$ & $1.51(0.60,3.81)$ & $1.8(0.5,6.37)$ \\
\hline $2500-3499$ & $123(32 \%)$ & $26(21 \%)$ & $97(79 \%)$ & $2.03(0.83,4.99)$ & $1.8(0.6,5.72)$ \\
\hline $3500-4499$ & $57(15 \%)$ & $10(18 \%)$ & $47(82 \%)$ & $1.61(0.57,4.57)$ & $1.1(0.3,4.61)$ \\
\hline \multicolumn{6}{|l|}{ tenancy } \\
\hline private & $293(76 \%)$ & $63(22 \%)$ & $230(78 \%)$ & $2.43(1.06,5.56) *$ & $1.5(0.5,4.30)$ \\
\hline \multicolumn{6}{|l|}{ Ethnicity group } \\
\hline Somali & $240(62 \%)$ & $45(19 \%)$ & $195(81 \%)$ & $.46(0.150,1.42)$ & $0.7(0.2,3.35)$ \\
\hline Amara & $77(20 \%)$ & $13(17 \%)$ & $64(83 \%$ & $.406(0.12,1.39)$ & $1.2(0.2,6.90)$ \\
\hline Oromo & $32(8 \%)$ & $11(34 \%)$ & $21(66 \%)$ & $1.048(0.29,3.84)$ & $2.3(0.4,14.62)$ \\
\hline
\end{tabular}




\begin{tabular}{|c|c|c|c|c|c|}
\hline \multirow{2}{*}{ Independent variables } & \multirow{2}{*}{ Frequency } & \multicolumn{2}{|c|}{ Access to Water Supply } & \multirow{2}{*}{ COR $(95 \% \mathrm{CI})$} & \multirow{2}{*}{ AOR (95\% CI) } \\
\hline & & Yes $(\%)$ & No (\%) & & \\
\hline Gurage & $22(6 \%)$ & $1(5 \%)$ & $21(95 \%)$ & $.095(0.10,0.93)$ & $0.4(0.0,8.30)$ \\
\hline Others & $15(4 \%)$ & $5(33 \% \mathrm{~V}$ & $10(67 \%)$ & 1 & 1 \\
\hline \multicolumn{6}{|l|}{ Type of water source } \\
\hline Public stand pipe & $33(9 \%)$ & $1(3 \%)$ & $32(97 \%)$ & $0.47(0.05,4.71)$ & $0.5(0.0,6.06)$ \\
\hline Vendor & $167(43 \%)$ & $1(1 \%)$ & $166(99 \%)$ & $0.09(0.01,0.89)^{*}$ & $0.0(0.0)$, \\
\hline From neighbour & $48(12 \%)$ & $3(6 \%)$ & $45(94 \%)$ & 1 & 1 \\
\hline \multicolumn{6}{|l|}{ Sex of household head } \\
\hline Male & $228(73 \%)$ & $55(19 \%)$ & $228(81 \%)$ & $1.0(0.57,1.77)$ & $0.81(0.24,2.7)$ \\
\hline Female & $83(27 \%)$ & $20(19 \%)$ & $83(81 \%)$ & 1 & 1 \\
\hline \multicolumn{6}{|l|}{ Family size } \\
\hline $1-3$ & $40(13 \%)$ & $12(23 \%)$ & $40(77 \%)$ & $2.925(0.87,9.85)$ & $4.4(1.2,16.1)$ \\
\hline $4-6$ & $121(39 \%)$ & $28(19 \%)$ & $121(81 \%)$ & $2.256(0.75,6.83)$ & $2.8(0.9,8.8)$ \\
\hline $7-9$ & $111(37 \%)$ & $31(22 \%)$ & $111(78 \%)$ & $2.723(0.903,8.208)$ & $2.4(0.8,7.7)$ \\
\hline$>10$ & $39(11 \%)$ & $4(9 \%)$ & $39(91 \%)$ & 1 & 1 \\
\hline \multicolumn{6}{|l|}{ Age of house head } \\
\hline $15-24$ & $41(12 \%)$ & $7(15 \%)$ & $41(85 \%)$ & $0.43(0.14,1.26)$ & $0.2(0.02,1.7)$ \\
\hline $25-34$ & $84(27 \%)$ & $21(20 \%)$ & $84(80 \%)$ & $0.63(0.26,1.5$ & $0.49(0.09,2.7)$ \\
\hline $35-44$ & $97(32 \%)$ & $27(22 \%)$ & $97(78 \%)$ & $0.7(0.3,1.6$ & $0.5(0.10,2.6)$ \\
\hline $45-54$ & $57(17 \%)$ & $10(15 \%)$ & $57(85 \%)$ & $0.4(0.16,1.18$ & $0.33(0.05,2.0)$ \\
\hline$>55$ & $25(9 \%)$ & $10(29 \%)$ & $15(71 \%)$ & 1 & 1 \\
\hline \multicolumn{6}{|l|}{ Religion } \\
\hline Muslim & $217(70 \%)$ & $54(20 \%)$ & $217(80 \%)$ & $.829(0.221,3.118)$ & $0.02(0.00,38.4)$ \\
\hline Orthodox & $84(26 \%)$ & $18(18 \%)$ & $84(82 \%)$ & $.714(.178,2.859)$ & $0.01(0.00,9.4)$ \\
\hline Protestant & $10(3 \%)$ & $3(23 \%)$ & $10(77 \%)$ & 1 & 1 \\
\hline \multicolumn{6}{|l|}{ Marital status } \\
\hline Single & $8(2 \%)$ & $1(11 \%)$ & $273(89 \%)$ & $.625(.031,12.410$ & $23.34(0.09,63.72)$ \\
\hline Married & $273(89 \%)$ & $70(20 \%)$ & $25(80 \%)$ & $1.282(.147,11.151$ & $3.22(0.07,14.5)$ \\
\hline divorce & $25(7 \%)$ & $3(11 \%)$ & $5(89 \%)$ & $.600(.051,7.012$ & $2.36(0.03,18.3)$ \\
\hline wisdom & $5(2 \%)$ & $1(17 \%)$ & $273(83 \%)$ & 1 & 1 \\
\hline
\end{tabular}

$*=$-value $<0.05, * *=$-value $<0.01, \mathrm{CI}=$ Confidence Interval, $\mathrm{COR}=$ Crude Odds Ratio, $\mathrm{AOR}=$ Adjusted Odds Ratio

\section{Discussion}

This study investigated access pattern of water supply in terms of source, distance, time, quantity and affordability among households in Jigjiga town in Ethiopia. The study found that about $56.7 \%, 90.9 \%, 92.2 \%, 35.3 \%$ and $44.8 \%$ of households had access to water in terms of source, distance, time, and quantity and cost respectively. Over all when the above criteria are computed based on WHO 2003 guideline $22 \%$ of the households had access to water supply but when water aid criteria included (cost affordability) the result indicates only 75 (19\%) households were accessible to water supply. The same study done in Ilorin East, Kwara State, Nigeria showed accessibility of water supply was $26 \%$ [13]. This indicated that the finding in Jigjiga town was lower than the study conducted in Nigeria. This gap might be due to the differences in water accessibility evaluation criteria.

The accessibility of water in terms of source for this study in Jigjiga town indicated that it was, 219 (56.7\%) of the households used pipeline water supply and the remaining 167 $(43.3 \%)$ households got water from vendors which was not improved source. This was lower than the study done on accessibility of water supply in terms of source in four regional states and 16 town of Ethiopia, which found that $79 \%$ of households were found using an improved water supply [10]. The accessibility of water in terms of source in Jigjiga town was found to be better than the study done in Awaday town that which was $39.4 \%$ [9].
The main possible reason for the difference in the coverage of accessibility in terms of source in these different towns might be the poor infrastructural arrangement in the town and institutional capacity, without which expansion of the pipe water supply coverage is impossible.

The study revealed that $351(90.9 \%)$ and $356(92.2 \%)$ households have access to water supply in terms of time and distance respectively. This was more or less consistent with a study conducted in Dukem town, that shows (83.9\%) and $82.4 \%$ ) of households were accessible in terms of distance and time respectively [14].

According to this study finding, only 170 (44.8\%) of households were accessible to water supply economically i.e. pay less than $5 \%$ of their monthly incomes based on the water aid 2011 criteria. Expenditure of household income on water showed that low, middle and high-income households spend an average of $24.12 \%, 11 \%$ and $2.67 \%$ of their income on water respectively. This finding was far from the study conducted in Nazareth town, where households from the low income areas spend, on average, $3.58 \%$ of their monthly income, whereas from that of middle and high income areas spend $1.49 \%$ and $1.02 \%$ of their monthly income on water per month [15].

The main reason for the difference in the expenditure for water might be due to the high operational cost needed for instalment of privet pipe Water supply, which prohibits the poor and consequently exposes them to more expensive water sources. This also might be due to comparatively small number of public standpipes, which could provide ample 
water supply for a small price, might leave the public to choose high price water.

The result of the study in Jigjiga town indicated that household heads with an education level of college \& above were $[(\mathrm{AOR}=4.2,95 \% \mathrm{CI}(1.0,18.06)]$ were more likely to be accessible to water supply compared to those household heads who cannot read \& write. This result was more or less similar to a study done in Cameroon where, household heads with increasing educational level were more likely to adopt an improved water source $(\mathrm{AOR}=0.113, \mathrm{P}<0.0371)$ [16]. This result of the study in Jigjiga town was also somewhat consistent with the same study conducted in Bomet municipality, Kenya which also showed that the type of water source used by the household was significantly influenced by the higher level of education (tertiary level) [17].

The study showed that there was varying average water consumption in liters per person per day with a varying type of water source. The average water consumption rate was 19.4 16.215 .6 and 16 liters per capita per day for those who used Privet pipe, public standpipe, Vendor and from neighbors respectively. This result was comparatively similar with a study conducted on water accessibility among households in Ambo Town, where the average litters per person per day consumption of households from private yard connection, public tap and vendor sellers were $10.55,8.93$ and 6.51 respectively [18].

This survey in Jigjiga town indicated that 136 (35.2\%) of them had access to water supply in terms of quantity. This fining was more or less similar with the study done in four regional states and 16 town of Ethiopia, which indicated that $60 \%$ of households using an improved water source reported using less than $20 \mathrm{lpcd}$. The volume of water used is known to be a critical factor in health outcomes [10].

The study was limited in subject/theme/ that means it limited to assess factors affecting accessibility of domestic water supply only (it doesn't include industries and consumptions by other sectors and its quality).

\section{Conclusion and Recommendation}

\subsection{Conclusion}

This study investigated status of water accessibility and associated factors among households at Jigjiga town. Water accessibility in study area is very low that mean only $19 \%$ of respondents were accessible water supply. Logistic regression analysis results showed that water accessibility was statistically associated with type of water source (AOR $=19.1,95 \%$ CI: (5.1, 71.39) and education level $(\mathrm{AOR}=4.21,95 \% \mathrm{CI}(1.0,18.06)$

\subsection{Recommendation}

1. Jigjiga Town water supply and sewerage authority and other stake holder

a) They should promote private pipe water connection services

b) They should work to increase public stand pipe with recommended households

c) They should improve reliability of water supply

d) They should control cost of water soled by vendors

\section{References}

[1] WHO, 2014b. INVESTING IN WATER AND SANITATION: INCREASING ACCESS, REDUCING INEQUALITIES UN-Water Global Analysis and Assessment of Sanitation and Drinking-Water GLAAS 2014.

[2] Zuin, V., Ortolano, L., Alvarinho, M., Rüssel, K., Thebo, A., Muximpua, O. \& Davis, J. 2011. Water supply services for Africa'surban poor: the role of resale. J. Water Health 9, 773-784.

[3] WHO and UNICEF 2014. Progress on Sanitation and Drinking-Water - 2014 Update. Switzerland.

[4] WHO, 2000. Global Water Supply and Sanitation Assessment 2000 Report World Health Organization and United Nations Children's Fund 2000, New York, USA.

[5] Central Statistical Agency [Ethiopia] and ICF International 2012. Ethiopia Demographic and Health Survey Addis Ababa, Ethiopia and Calverton, Maryland, USA, Central Statistical Agency and ICF International.

[6] U. N. General Assembly Res. 64/292, U. N. Doc. A/RES/64/292 (July 2010); Human Rights Council Res. 15/9, U. N. Doc. HRC/RES/15/60 (Oct. 2010).

[7] Bradley DJ and JK., B. 2013. Domestic Water and Sanitation as Water Security: Monitoring, Concepts and Strategy. Phil Trans R Soc A 371 (20120420). Downloaded from http://rsta.royalsocietypublishing.org/ on November 25, 2015.

[8] AlexanderKT., TesfayeY., Dreibelbis R., Abaire B. andFreeman MC. 2013 Sustainability and functionality of water systems in Millennium Water Alliance program areas.

[9] Mekonnen Abdisa and R. Uttama Reddy, 2014. Assessment of potable water supply in Awaday town in Ethiopia, International Journal of Social Science ISSN 2305- 4557, 30th January 2014. Vol. 19 No. 1 www.Tiloss.com

[10] Adank. M, et al. 2016, Water and sanitation services in small towns in Ethiopia Journal of Water, Sanitation and Hygiene for Development in press 2016.

[11] WHO 2003. Domestic Water Quantity, Service Level and Health. Guy Howard and J. Bartram. Geneva, Switzerland World Health Organization.

[12] Water Aid (2011) Policy guidelines: Water resource management. Water Aid in Nepal. Available at: www.wateraid.org/documents/plugin_documents/policy_guide lines_water_resource_management_5_september_2011.pdf.

[13] Tunde, A. M. 2013. Assessment of Households' Water Availability and Accessibility in Ilorin East L. G. A Kwara State, Nigeria

[14] Mohammed, A. I.. Zungu L. I and. HoqueM. E. (2011). Access to Safe Drinking Water and Availability of Environmental Sanitation Facilities among Dukem Town Households in Ethiopia. J Hum Ecol, 0000: 000-000 (0000). 
[15] Alebel Bayrou. 2002. Analyses of affordability and determinants of willingness to pay for improved water service in urban areas, strategy for cost recovery. A case study of Nazareth town, Ethiopia.

[16] Luc Armand Totouom Fotuè. 2013. Awareness and the Demand for Improved Drinking Water Source in Cameroon, International Journal of Economic Practices and Theories, Vol. 3, No. 1, 2013 (January), e-ISSN 2247-7225 www.ijept.org
[17] Koskei. E. C, Koskei. R. C, Koske. M. C and Koech. H. K, 2013. Effect of Socio-economic Factors on Access to Improved Water Sources and Basic Sanitation in Bomet Municipality, Kenya, Research Journal of Environmental and Earth Sciences 5 (12): 714-719, 2013 ISSN: 2041-0484; e-ISSN: 2041-0492

[18] Challa Deyessa. 2011. An assessment of urban water supply and sanitation, the case of ambo town. Addis Ababa, Ethiopia. 